\title{
Research on Services in the Manufacturing Industry based on a Holistic Viewpoint and Interdisciplinary Approach
}

\author{
Tomohiko Sakao, Christian Berggren, Mats Björkman, Christian Kowalkowski, \\ Mattias Lindahl, Jan Olhager, Jörgen Sandin, Erik Sundin, Ou Tang, \\ Patrik Thollander and Lars Witell
}

\section{Linköping University Post Print}

N.B.: When citing this work, cite the original article.

Original Publication:

Tomohiko Sakao, Christian Berggren, Mats Björkman, Christian Kowalkowski, Mattias Lindahl, Jan Olhager, Jörgen Sandin, Erik Sundin, Ou Tang, Patrik Thollander and Lars Witell, Research on Services in the Manufacturing Industry based on a Holistic Viewpoint and Interdisciplinary Approach, 2011, Functional thinking for value creation : proceedings of the 3rd CIRP International Conference on Industrial Product Service Systems, 27-32.

http://dx.doi.org/10.1007/978-3-642-19689-8_7

Copyright: Springer 


\title{
Research on Services in the Manufacturing Industry based on a Holistic Viewpoint and Interdisciplinary Approach
}

\author{
Tomohiko Sakao, Christian Berggren, Mats Björkman, Christian Kowalkowski, Mattias Lindahl, Jan Olhager, \\ Jörgen Sandin, Erik Sundin, Ou Tang, Patrik Thollander, Lars Witell \\ Department of Management and Engineering, Linköping University, Sweden
}

\begin{abstract}
This paper begins by consolidating industrial challenges and research issues concerning Product/Service Systems obtained through various activities by the authors. Based on this, it points out the importance of the holistic view in further research in this area so that PSS providers do not fall into local optimization. The intent of this contribution to our research community includes shedding light on interesting issues that thus far have been relatively invisible and with narrower scope.
\end{abstract}

Keywords:

Research priority, ManuServ, PSS, IPS ${ }^{2}$

\section{INTRODUCTION}

Given the significant interest in services in the manufacturing industry, Linköping University's Centre for Service Research in Manufacturing Industry (ManuServ) was formed in 2010. ManuServ is a research community which aims to advance the frontier in manufacturing-related service research. Concretely, its goal is advancing service knowledge acquisition and exploitation, thereby increasing the competitiveness of manufacturing firms. Integration of services with products are among the most crucial issues in ManuServ, where Product/Service Systems (PSS) is naturally a central topic.

Academics participating in ManuServ in collaboration cover a wide variety of disciplines, such as industrial marketing, R\&D, product development, service innovation, quality management, production system development, and production economics. One of its strengths lies in its large variety of different research disciplines.

Based on ManuServ's wide range of research experiences in various industries, summarized in Section 2, this paper first consolidates industrial challenges and research issues in Sections 3 and 4 , respectively. Then, Section 5 presents a discussion, mainly from a holistic viewpoint, which is crucial in research and practice in this area. Indeed, the intent of this initiative to the research community includes, by presenting a holistic viewpoint, shedding light on interesting issues that have thus far been invisible given their narrower scopes. Section 6 concludes the paper.

\section{BACKGROUND}

Section 2 summarizes various activities by researchers in ManuServ for more than ten years in the area of Product/Service Systems (PSS). Its aim is sharing with the reader our experiences and competencies that helped us arrive at our recognition of important industrial challenges and research issues, which are described later in Sections 3 and 4.

The research has been carried out in close cooperation with leading
Swedish and international companies and research institutions. Examples of projects, some of which are ongoing, are :

- Adapting Manufacturing Strategy to Industrial After-Sales Service Operations (Financed by: IMIE + Dept. of Production Economics, LiU)

- Energy Services in Industry (Financed by: The Swedish Energy Agency)

- Expanding Engineers' Opportunities: from Ecodesign to Integrated Product Service Engineering (Financed by: The Swedish Association of Graduate Engineers)

- Flexible Business Models for Sustainable Competitive Advantage - Swedish Industrial Companies' Transition towards Service Orientation (Flexkraft) (Financed by: VINNOVA)

- Integrated Product Service Engineering (Financed by: VINNOVA) Integrated Product Service Offerings (Financed by: Swedish Environmental Agency)

- Integrated Product Service Offerings (Financed by: Swedish Environmental Protection Agency)

- Integrated Product Service Offerings of the Railway Infrastructure System (Financed by: Swedish Transport Administration)

- Integration of Developing Products and Services towards Customer-oriented Solution Provider (Financed by: a Swedish manufacturer)

- Managing Innovation Processes for a Business-Driven Collaborative Network (Financed by: VINNOVA)

- Mapping of Integrated Product Service Offerings in Sweden (Financed by: VINNOVA)

- Routinized Activities for Balancing Products and Services (Financed by: Division of Project, Innovation and Entrepreneurship, LiU)

- Solvent-Free Industrial Cleaning (Financed by: ProEnviro)

- Technology - Business - Design for successful functional 
sales (Financed by: VINNOVA)

These projects cover various disciplines and different aspects, including environment and energy ${ }^{1}$. Figure 1 depicts the processes of interest (IPSO, standing for Integrated Product Service Offering, is used as an equivalent term to PSS in this figure).

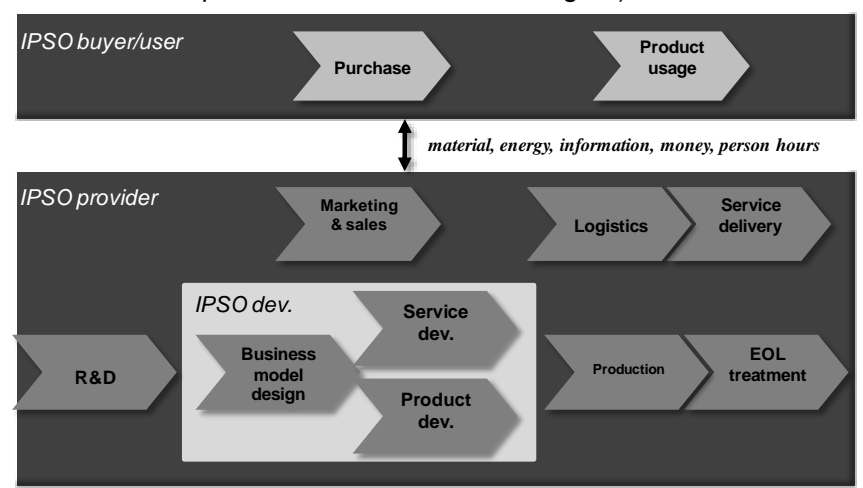

Figure 1: Processes of interest in ManuServ

\section{INDUSTRIAL CHALLENGES}

\subsection{Marketing and sales}

In order to develop, sell, and deliver PSS, several marketing and sales practices need to be revised, and many new capabilities are needed in goods-centric firms. For example, many challenges relate to the manufacturing and R\&D-orientated corporate culture, lack of top management commitment to service strategies, the sales organisation's focus on equipment sales, and incentive systems and key performance indicators (KPIs) which disfavour service operations. In a survey of more than 300 manufacturing companies, [1] identified pricing as a major challenge facing manufacturing firms. Thus, pricing is an important challenge among others. In terms of pricing, many find it easier to price their goods than their services. In particular, they have difficulties in estimating the value of the "intangibles" associated with services. In addition, many manufacturing firms have traditionally given away service in order to make a sale, i.e. services are free. Sales forces typically find it more difficult to sell services than products, and the financial incentive systems are often not designed to reward this more challenging behaviour [2]. For PSS, the firm's charges are often based more on the customer's value-in-use than on the monetary exchange value $[3,4]$. Specifically, the process-orientation of solutions implies that pricing policy is linked, to varying degrees, to outcomes delivered to the customer. The price can be fixed, such as when a fixed fee is charged for a given level of availability in outcome-based agreements, or dynamic, as in a "gain-sharing" arrangement with payments directly linked to the customer's business performance [5].

However, pricing-related challenges do not only concern services. What is challenging at a higher level is pricing different services and products of a PSS along the entire product lifetime. Our observations of a manufacturer providing long-term products has found them charging relatively lower prices on products at instalment but higher prices on services (incl. spare parts), which has led to low customer satisfaction. This is at present recognized as a problem for increasing customer satisfaction in that company. This issue needs investigation with a holistic view on another dimension.

\footnotetext{
${ }^{1}$ For more details of the projects above and their associated publications, see manuserv.iei.liu.se.
}

A related challenge that firms need to manage is to have different revenue mechanisms (e.g. transactional and value-based pricing approaches) in parallel. Firms offering PSS have to manage dual revenue models, i.e. both the traditional one where customers pay for service hours and parts used and one where the customer pays a fixed cost per time period, regardless of any fluctuations in the provider's service activity costs [2].

New industrial services and PSS also require companies to have the ability to visualize service-based and relationship-based values, i.e. to communicate and demonstrate the values both internally and externally. Managers need be able to make use of several different visualization strategies, depending on the actual content of the offering and its position in the development process. Value visualization strategies have traditionally focused on external sales activities. However, companies need to have a broader approach to visualization, being able to visualize the (potential) value during the service development process, during sales, and during service provision, as well as including different visualization techniques. Value visualization has become vital for winning new contracts and retaining existing ones. It is therefore a strategic resource that managers need to pay attention to, and continuously develop, in order to compete with PSS [6, 7].

\subsection{Business model development}

Manufacturing firms have typically exhibited a product and technology orientation, and many of them are relatively new to service logic and to service innovation. Service development often becomes more complex in manufacturing firms than it does in pure service firms, since manufacturing firms have a core product that has traditionally carried most of the value and which is heavily embedded in the company culture [8, 9]. Thus, identifying and implementing service-based business models in goods-centric companies is often a very long-term process [10]. Firms need to focus on all areas of their business models in a holistic fashion, and not just change isolated elements. Among other challenges, companies must develop their abilities to build relationships with customers and to advance a dynamic service offering portfolio that is adaptive to changing customer needs [9]. From a development perspective, many firms provide services in an unstructured manner and lack the capability to sense market opportunities. Furthermore, many firms have problems getting investment decisions and commitment and they lack the necessary service infrastructure and technology [8]. Therefore, firms need to balance exploration and exploitation, and local and central innovation and learning. In contrast to goods innovation, many new services are developed locally, often in an ad hoc manner in close interaction with customers [2, 11]. Firms should not only blueprint complex product development models but also consider service-specific aspects, such as more iterations and interactions with lead customers. This also relates to marketing and organizational issues, such as developing measures and sales tools, and changing existing mindset, norms, and values [8].

\subsection{PSS development and R\&D}

Solutions in order to improve service (including maintenance and remanufacturing) are often ignored when designing new products. In other words, there is lack of feedback from the field. Regarding service design, our observations found that service is often added on already existing products (e.g. [8, 12]). Integration between product design and service design is weak. In these cases, there is obviously a risk of sub optimisation (and even one of ending up with 
unsuccessful solutions). For this problem, developing physical products (artefacts) in parallel to adjacent services instead of having a traditional sequential development needs to be established (also argued in [13, 14]). This needs an integrated approach across different divisions, especially in large firms.

In particular, developing models and methods that facilitate the integration of the new requirements that PSS put on the development process is also a challenge (see e.g. [15]). Another challenge in integration within a firm is integrating PSS design methods, if any, and customer value management methods. Some companies have customer value management systems, but face difficulty in making use of it to conduct PSS design effectively.

New requirements on development, products, offerings and operations might occur and the need for crosstalk between different functions increases. The majority of the functions in the organization need to work in an integrated manner to a greater extent. Processes need to be parallel, flexible, frontloaded and to support learning. Moreover, contemporizing and connecting support tools and systems to the processes might be another challenge. System and infrastructure need to support reversed logistics, not only with physical material, but also with information, both upstream and downstream.

Among others, a great challenge for industrial manufacturing companies moving towards PSS is that the structure, including processes, support tools and systems, are not yet completely sufficient for PSS. A need for new features might occur and there is most often a demand for an increased holistic view that attends to the complete product life-cycle. Examples on new features required are fleet management, product monitoring and return systems. Furthermore, content based visualizing system displaying flow of value and also material, energy, information and man hours may be critical.

Looking at the service design part, effective and efficient service development in goods-centric companies is an issue at present, since that was not so important before.

Looking at an earlier phase, e.g. R\&D, evaluating and improving $R \& D$ projects towards increasing customer value is also an issue. Some companies find the need to modify the procedure of engineering activities prior to product design. One reason is the emerging need to focus on customer value even in R\&D, which used to be often oriented toward technology push. For instance, new technology can support reducing the system downtime and thereby adding customer value. The challenge is to be able to do this at the same time as the costs for Maintenance, Repair and Overhaul (MRO) is minimized (see e.g. [16]).

\subsection{Production}

An ideal product to sell is the product you don't need to produce, and PSS opens the door for this opportunity if you as a PSS provider can take back used products and with minimal effort can reuse them again for existing or new customers. However, in order to do so in an efficient and effective manner, the products must be engineered for take-back and remanufacturing (see previous section). Previous research [12] has shown that this is not often the case.

PSS, when including having take-back systems, change the way of looking at production. The focus in production moves from producing as many products (based on virgin components) as possible into, as long as it is economically and technically possible, producing products based on used products and components with as little use of new components as possible.
PSS put new requirements on the products and the production systems throughout the products' technical and economic lifecycles [17]. For instance, when using return items, it creates some challenges in production and planning, due to the uncertainty of return time, quantity, and quality. In addition, returns can be substantially diversified, thus creating difficulties in applying "standard" production process. At the same time, those challenges, if handled in the development process, can be prevented or eased and turned into advantages because of the cost reduction reuse of products can give. It could mean that a supplier sets up a system for reverse logistics and remanufacturing in order to benefit from the economic and environmental potential found in the PSS business model [18]. Toyota Material Handling is an example of a company that has done just that. They provide material handling through forklift truck rental agreements, and have set up a fleet management centres including product monitoring and remanufacturing activities throughout Europe [18].

To summarize, based on ManuServ's previous research, PSS business models elucidate the potential of developing models for setting up e.g. preventive maintenance, product monitoring, product return systems / reverse supply chains, part exchange systems, remanufacturing / recycling and fleet management centres.

\subsection{Supply chain management}

In case the business involves return, the reverse logistics could be a major problem. It is important to identify the return network, its connection with the forward network, and acquisition/sorting issues. It is also strategically important to balance the returns and the demand of returns (considering the production life cycle issue). In case the business does not involve returns, the integration of cost, market and knowledge should be a concern in defining a supply chain structure.

\subsection{Service delivery}

The lack of a service delivery organization and the risk of building up one - i.e. entering a new field - is for many traditionally productfocused companies a huge challenge since they need new competencies, management, etc. Added to this is the economic challenge in building up the service delivery infrastructure, and the concern of what will happen if the demand for the service disappears. A more detailed but important challenge is to maintain the quality of the delivered offering. For products it is easier to optimize based on fraction of a percent, but when optimizing service delivery, i.e. working with people and not machines, it is trickier to optimize and the fluctuation of the results increases.

For companies with an existing external service delivery organization designed for traditional sales of products, a move into PSS offerings might be a big challenge if they cannot control their service organization or cannot build up a parallel one suited for PSS. Traditionally, service delivery organisations are often built up on earning money from service and spare part sales. The problem is that when selling PSS offerings, e.g. get paid for the function, spare parts and service become costs instead of incomes for the PSS provider. This might imply tensions and problems in the existing service delivery organisation. Hence, it can be a great challenge to implement a new mindset from the very top of the organization, all the way down to the development and the operations.

When designing PSS offerings, managing internal data about ongoing service delivery with their contracts (including the planned 
and actual costs) has been identified to be a big challenge [4]. This data contributes to more precise projection of uncertain events during a contract period, and assists the provider in making decisions on uncertainty allocation. However, this needs to be tackled from a company-wide perspective, because this kind of data will be related to existing systems such as the ERP (enterprise resource planning) system.

\subsection{Managing energy and material consumption - application-oriented challenges}

Increasing raw material and energy prices have become an problematic issue for both producers and users. In line with this, some larger companies have also realized that if they want to increase their market, e.g. in China and India, they need to change their way of offering into more material and energy efficient and effective solutions. If not, they foresee that their own increased need of material and energy will have a notable negative impact on the price levels and will be an obstacle for their ambitions. At the same time, society's focus on environmentally-related issues has forced many companies to rethink their way of offering goods and services. Since environmental problems are tightly linked to energy and material use, they need to find new solutions that reduce this use.

This has led to an increasing focus and interest in reducing the use of material and energy in order to cut down their costs, and PSS has in this context become an interesting solution.

Looking at energy consumption, great potential for energy efficiency exists in industry, but the adoption of energy efficiency measures is often inhibited by various barriers. Different means to overcome these barriers and promote energy efficiency in industry exist, one of the most promising being energy services. Earlier research shows that while many barriers could be overcome by energy services, the industry's ranking and adoption of energy services is very low. Therefore, developing methods on how to integrate/promote energy services in manufacturing companies is an interesting issue.

Regarding raw material consumption, prior research indicates the large potential for more efficient and effective use. However, to do so, products used in the offerings need to be designed to fit into the PSS business model (see previous section about product development and production).

\subsection{Organizational management}

One major industrial challenge facing manufacturing companies trying to increase their emphasis on services is that the organization is not ready to work with services [1] [2]. Many manufacturers have embarked on services without any clear strategy. These firms have viewed their service transition as another growth initiative, and have failed to understand the organizational change required. Most of a manufacturing company's tacit knowledge is with its products, rather than existing or potential service offerings, and many companies had attempted to market new services in the same way as they had always sold new products - that is, by adding new responsibilities to existing managers' roles while maintaining current organizational structures, practices and incentives.

As the division between goods and services becomes ever more blurred, there is an increasing need for cooperation between the service and the product organizations [19]. Applying a service logic means that the traditional division between goods sales and aftersales services becomes outdated. Instead, the customer relationship becomes the centre of the offering regardless of its combination of services and goods. Thus, a transition to service logic implies much more than an increased emphasis on services; it implies a reframing of the purpose of the firm and its role in value co-creation. For instance, it means that research and development, sales, service, finance, human resources, and other local and central organizational functions must work together to a greater extent than is usually the case in manufacturing firms [2, 20]. What has been found among large firms delivering PSS is that the product development department often has a long tradition and is much larger than the service development department, which makes it harder for the "service people" to have their voice heard [21]. Further, the infusion of service in manufacturing firms means that more service processes and interfaces have to be managed simultaneously [22].

Very few manufacturing firms have all the physical and service components and all the competencies needed to provide PSS. Therefore, firms are to various extents dependent on partner firms and other actors in the business network. From a managerial point of view, firms need to determine which services and service-related capabilities to provide themselves and which can, or should, be externalized. Furthermore, other firms, such as consultants, may have significant influence on the customers' specifications and inquiries, and, thus, these network relationships must be managed in accordance with the firm's market and service strategies [2]. This is particularly challenging if firms operate in antagonistic service networks with limited trust and communication among actors, and a considerable amount of power play. In such contexts, actors strive to maximize their own value from a zero-sum game perspective, and there is no room for "real" partnerships [23].

\section{RESEARCH ISSUES}

\subsection{Towards a value-oriented provider}

There are several research avenues of interest that relate to service infusion and value creation and capture through new industrial services and PSS. Manufacturing firms need to focus on these issues in a holistic and interdisciplinary fashion, due to the systemic nature of value creation and customer value management. Research in this area is scarce, however, and there are many calls for further research [24, 25].

For example, managing a cultural shift from maximizing unit sales to selling performance and facilitating customer value co-creation is yet an under-researched area, including issues such as shifting from a goods-centric to a service-oriented sales force, coordinating and determining the degree of integration between local and central, and between goods, services, and solutions units, and aligning goods, services, and solutions strategies.

Furthermore, service and business model innovation should be a research priority [26]. It includes issues such as identifying the role of local and central units in the innovation process, identifying how and when to involve customers and partners, and generating, evaluating, and realizing innovation ideas. More research is called for regarding developing a competitive offering portfolio and PSS value propositions. For example, research should facilitate a deeper understanding of what perceived benefits and sacrifices should be emphasized, and the relative emphasis on value-in-exchange and value-in-use in value propositions [27]. How should firms balance requirements on cost-efficient operations and standardized processes with customization and flexibility, how can service modularity be utilized, and how can we better understand 
customers' value-creating processes and which customers want services and PSS?

Finally, research should focus on how firms can derive equitable value capture. That is, determining how to share gains and losses across a service system. Researching service systems and business networks implies a holistic approach, and other areas of interest include: optimizing service networks and value constellations, and improving intra- and inter-organizational collaboration locally and globally.

\subsection{Basic research}

Looking at fundamental insights from conventional engineering, revisiting the well-known relationship between the cost and the influence of each lifecycle phase (or stage) can be a research issue. E.g. a rule, "the task clarification stage of product design accounts for only $10-15 \%$ but determines $50-70 \%$ " of the total cost is well known. But, on the other hand, a PSS provider has an opportunity to reduce $30-40 \%$ of the total lifecycle cost of a customer through provided services. More related pieces of information are expected to be collected from different cases. Apparently, a substantial change to such rules in comparison to those in a product sales business is foreseen. It would be valuable for companies to generalize such knowledge in PSS, even though it depends on the types of products.

\subsection{Application-oriented research}

The potential for energy services in the non-trading sector of the company is stated to be vast. Related to the need for mitigation of global climate change, Energy Services is stated to play a key role. However, research in the area is scarce, both in relation to theoretical ideas and also in terms of bottom-up studies of how Energy Services are actually implemented in manufacturing companies. This may need an interdisciplinary approach due to its different types of barriers (see [28]).

\section{Discussion}

In our research we have found that services in manufacturing have received greater attention lately due to several reasons. One reason is that there is more for the manufacturers to make profit on besides the pure physical products. Changing the manner which the manufacturer makes profit needs a new mindset in the internal organization, e.g. the service department needs to get more attention regarding maintenance schemes and systems of reverse logistics and remanufacturing, where suitable. In addition, these people's needs also must be considered more in the development of business models and product design. All this should be conducted with the aim of gaining a holistic view of what the manufacturers are offering their customers.

The description of the industrial challenges and research issues in Sections 3 and 4 highlight the importance of the holistic view in this research theme. Therefore, ManuServ aims in particular at tackling industrial challenges with a holistic viewpoint to avoid local optimization within a firm or a group of companies within the same value chain. In order to deal with one industry challenge, several other interdependent ones frequently need to be coped with. For example, organizational and managerial challenges often need to be overcome in order to succeed with new marketing and sales practices, supply chain management, PSS and business model development, etc. Likewise, PSS development and design processes and routines, marketing and sales metrics, etc. may need to be revised in order to successfully implement organizational changes.

The ManuServ temple in Figure 2 describes the basic idea behind the ManuServ initiative - a temple needs several pillars to become robust. A PSS company cannot simply focus on one area to be successful - they need to balance and modify parameters from all the described areas. The idea is to link together different PSS research areas and their researchers in order to achieve cross communication and initiate new interdisciplinary research that take advantage of the opportunities to study the challenges from different perspectives and evaluate different ways of doing things. An example could be how the design of a product and service could affect the service delivery and business model and the interactions between those three areas.

When aiming for an improved way of working, adjusted to PSS, those types of changes are often a long term process and there is a great need for being assiduous. There is also a challenge of comprehending which capabilities that is realistic to develop and where to depend on partners.

As described in Section 3, previous research has generated new knowledge and also identified numerous relevant research issues for each described research area. However, the researchers behind the ManuServ initiative believe it is a problem that the links between those research areas today are so weak and undeveloped. They believe that PSS research would be more successful with a more integrated and holistic approach. At the same time, it is a bit paradoxical that the two basic ideas behind the PSS concept are the lifecycle perspective and integrated approach. It is natural to assume that the very different research areas, as described in Section 3, as are linked to one another. In other words, changes in one will affect the other, and it ought to be possible to balance different parameters from different areas between them. This is also partly highlighted in Section 3.

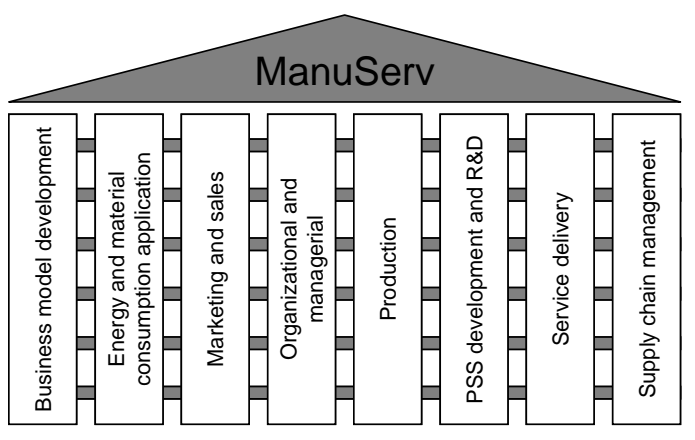

Figure 2: The ManuServ temple.

Note: The grey lines between the research areas illustrate linkages and communication between the research areas.

\section{CONCLUSION}

This contribution presented the authors' recognition of important industrial challenges and research issues about Product/Service Systems obtained through various activities by researchers in ManuServ. Based on this, it pointed out the importance of the holistic view in researching this area. This was shown to be crucial from the different problems and challenges exemplified in this contribution. 


\section{ACKNOWLEDGMENTS}

We extend our sincere gratitude to the Swedish and international companies who provided us with invaluable experiences in this area.

\section{REFERENCES}

1. Brown, S.W., A. Gustafsson, and L. Witell, Strategy beyond Products, in The Wall Street Journal. 2009.

2. Kowalkowski, C., Managing the Industrial Service Function. 2008, Linköping University: Linköping.

3. Nordin, F. and C. Kowalkowski, Solutions offerings: a critical review and reconceptualisation. Journal of Service Management, 2010. 21(4): p. 441-459.

4. Kowalkowski, C., What does a service-dominant logic really mean for manufacturing firms? CIRP Journal of Manufacturing Science and Technology, 2011.

5. Kowalkowski, C., P.-O. Brehmer, and D. Kindström, Managing industrial service offerings: requirements on content and processes. International Journal of Services Technology and Management, 2009. 11(1): p. 42-63.

6. Kindström, D., ed. Creating Business Out of Industrial Offerings. 2009, MTC.: Stockholm, Sweden. 156-172.

7. Kowalkowski, C. and D. Kindström, Value visualization strategies for PSS development, in Introduction to Product/Service-System Design, T. Sakao and M. Lindahl, Editors. 2009, Springer: London. p. 159-182.

8. Kindström, D. and C. Kowalkowski, Development of industrial service offerings: a process framework. Journal of Service Management, 2009. 20(2): p. 156-172.

9. Kindström, D., Towards a service-based business model - Key aspects for future competitive advantage. European Management Journal, 2010. 28(6): p. 479-490.

10. Gebauer, H. and E. Fleisch, An investigation of the relationship between behavioral processes, motivation, investments in the service business and service revenue. Industrial Marketing Management, 2007. 36(3): p. 337348.

11. Gremyr, I., N. Löfberg, and L. Witell, Service innovations in manufacturing firms. Managing Service Quality, 2010. 20(2): p. 161-175.

12. Sakao, T., et al., How Are Product-Service Combined Offers Provided in Germany and Italy? - Analysis with Company Sizes and Countries -. Journal of Systems Science and Systems Engineering, 2008. 17(3): p. 367381.

13. Sakao, T. and Y. Shimomura, Service Engineering: $A$ Novel Engineering Discipline for Producers to Increase Value Combining Service and Product. Journal of Cleaner Production, 2007. 15(6): p. 590-604.

14. Sakao, T., et al., Modeling Design Objects in CAD System for Service/Product Engineering. Computer-Aided Design, 2009. 41(3): p. 197-213.
Sundin, E., M. Lindahl, and W. ljomah, Product design for product/service systems - design experiences from Swedish industry. Journal of Manufacturing Technology Management, 2009. 20(5): p. 723-753.

16. Candell, O., R. Karim, and P. Söderholm, eMaintenanceInformation logistics for maintenance support. Robotics and Computer-Integrated Manufacturing, 2009. 25(6): p. 937-944.

17. Sundin, E., Life-cycle perspectives of Product/ServiceSystems: in design theory, in Introduction to Product/Service-System Design, T. Sakao and M. Lindahl, Editors. 2009, Springer: London. p. 31-49.

18. Sundin, E. and B. Bras, Making functional sales environmentally and economically beneficial through product remanufacturing. Journal of Cleaner Production 2005. 13(9): p. 913-925.

19. Gebauer, H., E. Fleisch, and T. Friedli, Overcoming the Service Paradox in Manufacturing Firms. European Management Journal, 2005. 23(1): p. 14-26.

20. Kowalkowski, C. What does a service-dominant logic really mean for manufacturing firms? in 2nd CIRP Intergrated Product-Service Systems (IPS $\left.{ }^{2}\right)$ Conference. 2010. Linköping.

21. Sundin, E., et al. Industrial Challenges for Product/Service Systems: Experiences from a large company network in Sweden. in CIRP IPS2 Conference. 2009. Cranfield.

22. Kowalkowski, C. and P.-O. Brehmer, Technology as a driver for changing customer-provider interfaces: Evidence from industrial service production. Management Research News, 2008. 31(10): p. 746-757.

23. Matthyssens, P. and K. Vandenbempt, Moving from basic offerings to value-added solutions: Strategies, barriers and alignment. Industrial Marketing Management, 2008. 37(3): p. 316-328.

24. Lindgreen, A. and F. Wynstra, Value in business markets: What do we know? Where are we going? Industrial Marketing Management, 2005. 34(7): p. 732-748.

25. Ulaga, W. and A. Eggert, Value-Based Differentiation in Business Relationships: Gaining and Sustaining Key Supplier Status. Journal of Marketing, 2006. 70(1): p. 119-136.

26. Ostrom, A.L., et al., Moving Forward and Making a Difference: Research Priorities for the Science of Service. Journal of Service Research, 2010. 13(1): p. 4-36.

27. Kowalkowski, C., Dynamics of value propositions: insights from service-dominant logic. European Journal of Marketing, 2011. 46(1/2).

28. Thollander, P., J. Palm, and T. Sakao. Increasing industrial energy efficiency through energy services - an interdisciplinary approach with engineering- and social science aspects. in The 2nd CIRP International IPS2 Conference. 2010. Linköping. 
